\title{
Investigating the particle precipitation of a moving cusp aurora using simultaneous observations from the ground and space
}

\author{
Satoshi Taguchi ${ }^{1,2,3^{*}}$, Keisuke Hosokawa ${ }^{1,2}$ and Yasunobu Ogawa ${ }^{4}$
}

\begin{abstract}
Using observations of a moving cusp aurora from a high-sensitivity all-sky imager at Longyearbyen, Svalbard, and in situ observations of the precipitating particles from a spacecraft that flew over the aurora, we examined the particle precipitation features in the early and final stages of the moving cusp aurora. We focused on two auroral structures created near noon, separated by approximately 3 min, during a southwestward interplanetary magnetic field (IMF) condition on 17 December 2012. The second auroral structure occurred when the IMF turned further southward. Immediately after the appearance of the latter structure, the two auroral structures were adjacently situated, and the DMSP F18 spacecraft passed through these regions. A detailed comparison of the data from particle spectrometers onboard the spacecraft and the $630 \mathrm{~nm}$ aurora image data demonstrates that the ion precipitation in the young cusp aurora (i.e., second auroral structure) had a high energy flux, whereas that in the old cusp aurora (i.e., first auroral structure) had a very low energy flux. For the electron precipitation, the features in both regions were found to be very similar; the energy flux at approximately $100 \mathrm{eV}$ often exceeded $1 \times 10^{9} \mathrm{eV} \mathrm{cm}^{-2} \mathrm{~s}^{-1} \mathrm{sr}^{-1} \mathrm{eV}^{-1}$ in both regions. This indicates that the electron precipitation in the moving cusp aurora is maintained at a high flux level over a certain interval from its starting time. Thus, we suggest that the electron precipitation flux in the moving cusp aurora is controlled by a mechanism independent of the ion precipitation.
\end{abstract}

Keywords: High-latitude ionosphere; Aurora; Particle precipitation; Cusp

\section{Background}

A moving mesoscale auroral structure, which is characterized by high red line intensities, is a typical phenomenon in the dayside cusp of the high-latitude ionosphere. Its motion generally has a poleward component and very often also has a strong azimuthal component. As has been shown by many researchers (e.g., Sandholt et al. 1986; Lockwood et al. 1989; Fasel 1995; Sandholt and Farrugia 2003; Oksavik et al. 2004; Taguchi et al. 2012), the azimuthal motion is eastward or westward, which is consistent with the direction of the interplanetary magnetic field (IMF) $B_{\mathrm{Y}}$-related tension force arising from the curvature of the open magnetic field line after reconnection on the dayside magnetopause.

\footnotetext{
* Correspondence: taguchi@kugi.kyoto-u.ac.jp

${ }^{1}$ Department of Communication Engineering and Informatics, University of

Electro-Communications, Chofu, Tokyo 182-8585, Japan

${ }^{2}$ Center for Space Science and Radio Engineering, University of

Electro-Communications, Chofu, Tokyo 182-8585, Japan

Full list of author information is available at the end of the article
}

A moving auroral structure that is observed well away from the main red line auroral band in the daytime sector is recognized as being the ionospheric signature of open magnetic flux motion driven by patchy or intermittent reconnection, known as a flux transfer event (FTE) (Haerendel et al. 1978; Russell and Elphic 1978). For a moving auroral structure that appears to be embedded in the red line auroral band, however, it is difficult to determine whether such a structure is the signature of an FTE. However, this auroral structure should also be located in the open magnetic field line region because the open/closed field line boundary generally coincides with the equatorward edge of the red line auroral band (Milan et al. 1999).

Immediately after the open magnetic field line is created by reconnection, magnetosheath plasmas (both electrons and ions) stream into the flux tube. Since the flux tube is moving, the injected particles with higher (or lower) velocities reach the ionosphere after they travel a shorter (or 
longer) distance. For ions, this behavior is observed over a period of several hundred seconds (Lockwood and Smith 1994) because ion velocities are typically comparable to the velocity of the flux tube. The ion energy flux also tends to decrease with increasing distance from the origin of the open flux tube, as is inferred from the results of the modeling of the particle precipitation for steady-state reconnection by Onsager et al. (1993).

For the electron precipitation in the moving cusp aurora, it is still not understood how the electron precipitation changes with increasing distance from the origin of the open flux tube. Satellite observations immediately inside the magnetopause have demonstrated the motion of flux tubes containing enhanced magnetosheath-like electrons (Owen et al. 2001). Since electrons have high speeds along magnetic field lines, they may come down to the ionosphere in time scales on the order of seconds, suggesting that the electron features of the ionospheric signature of the open flux tube reflect the spatial change in the magnetosheath density as a function of the downstream distance from the reconnection point.

Another possibility is that the precipitating electrons are affected by the ions that are injected with them, rather than simply reflecting the spatial change in the magnetosheath. Burch (1985) suggested that the cusp electrons follow the ions to maintain charge neutrality. If this behavior is operative in the flux tube of the moving cusp aurora and the mechanisms for maintaining the behavior do not change significantly with increasing distance from the origin of the flux tube, a fixed relationship may be seen between the features of the precipitating electrons and those of the precipitating ions, irrespective of the distance from the origin of the open flux tube.

At ionospheric heights, it is difficult to discern the evolution of the moving particle precipitation region using in situ data from a single spacecraft because the speed of low-altitude spacecraft is considerably greater than the speed of the precipitation region. The data obtained by a spacecraft would simply reflect the spatial structure inside the region without providing any information on its evolution. One powerful tool that does provide information on the evolution of the precipitation region is the all-sky imager. An all-sky imager can be used to understand when and where auroral structures are created and how they subsequently move. If an allsky imager observes multiple moving auroral structures whose elapsed times from their appearance differ and a spacecraft flies over these structures, then the spacecraft data can provide information on how the precipitation region changes with elapsed time from the appearance of the structures or with increasing distance from their points of origin.

For a single moving auroral structure, Oksavik et al. (2005) presented a simultaneous observation event of this type. Data from the ion drift meter on the Defense Meteorological Satellite Program (DMSP) F13 spacecraft for this event indicated the presence of mesoscale convection for a moving cusp aurora, whereas the precipitating particle data from this satellite did not show any prominent signatures. This latter result was presumably due to the fact that the satellite observation was made after the aurora disappeared (10:12:00 UT in Figure four of Oksavik et al. 2005). A moving cusp aurora has a short lifetime, typically 3 to $4 \mathrm{~min}$ (Fasel 1995). This short lifetime also makes it rare for their presence to coincide with the measurements of in situ spacecraft.

In this paper, we report results obtained on 17 December 2012 from the simultaneous observation of two cusp auroral structures by an all-sky imager and a spacecraft. We show the motion of the two auroral structures near local noon using the $630 \mathrm{~nm}$ auroral image captured by the all-sky imager. One auroral structure arrived at the satellite position approximately $230 \mathrm{~s}$ after its initial appearance (although the height of the aurora was much lower than the altitude of the satellite), whereas the other arrived at a similar position only $60 \mathrm{~s}$ after its initial appearance. We present observations of the precipitating particles made by the DMSP F18 spacecraft that flew over these auroral structures and show the precipitation features of the ions and electrons in the young and old flux tubes (i.e., the flux tubes of the auroral structures that appeared second and first, respectively).

\section{Methods}

\section{Instrumentation}

The instrumentation used in this study consists of a ground-based all-sky imager and particle spectrometers on the DMSP F18 spacecraft, which flew at an altitude of approximately $840 \mathrm{~km}$. The all-sky imager uses an electron multiplier charge-coupled device (EMCCD) camera (Hamamatsu, C9100-13, Hamamatsu, Japan) with an imaging resolution of $512 \times 512$ pixels and measures emission at two wavelengths, 557.7 and $630.0 \mathrm{~nm}$, using narrow passband interference filters. This ground-based imager has been operating in Longyearbyen, Norway, (geographical latitude $78.1^{\circ} \mathrm{N}$ and longitude $16.0^{\circ} \mathrm{E}$ ) since October 2011 (Taguchi et al. 2012). As shown in Taguchi et al. (2012), the $630.0 \mathrm{~nm}$ (red) line data from this EMCCD camera can provide detailed information about the dynamic features of moving cusp auroral structures. The high sensitivity of this camera is also very effective for identifying the structure of polar cap patches (Hosokawa et al. 2013a, 2013b, 2014; Sakai et al. 2014). Thus, in the current study, we used $630.0 \mathrm{~nm}$ wavelength images.

In the first observation season, from the end of October 2011 to the end of February 2012, we obtained $630.0 \mathrm{~nm}$ data with an exposure time of $4 \mathrm{~s}$ per image. For the 
second year of observation, which includes the event studied in this paper, we modified the observation mode slightly so that the $630.0 \mathrm{~nm}$ images could be obtained with an exposure time of $1 \mathrm{~s}$ in addition to the exposure time of $4 \mathrm{~s}$. For this study, we used the imaging data with an exposure time of $1 \mathrm{~s}$. As is demonstrated later, images with this short exposure time were more helpful for identifying the location of auroral brightening, even though the data were not obtained at regular intervals, because of the constraints of the software controlling the automated observation system.

The particle spectrometers on the DMSP F18 satellite measure precipitating electrons and ions with energies between $30 \mathrm{eV}$ and $30 \mathrm{keV}$ once per second (Hardy et al. 1984). Since electron precipitation with an energy of approximately $100 \mathrm{eV}$ strongly affects the $630.0 \mathrm{~nm}$ emission rate (e.g., Roble and Rees 1977), out of the full available energy range of the spectrometer, we concentrated on the electron data from three energy intervals near $100 \mathrm{eV}$, specifically at approximately 70, 100, and $150 \mathrm{eV}$.

\section{Observations of the cusp aurora on 17 December 2012}

Figure 1 shows the $630.0 \mathrm{~nm}$ all-sky image taken at 08:26:52 UT. The all-sky image is projected onto an Earth-centered sphere at a height of $250 \mathrm{~km}$, which is the typical altitude for a cusp aurora (e.g., Sandholt et al. 1990). A longitudinally elongated emission band (bluish color in Figure 1) was present across the entire field of view and spanned 09:30 to 13:30 magnetic local time (MLT). The postnoon portion of this auroral oval

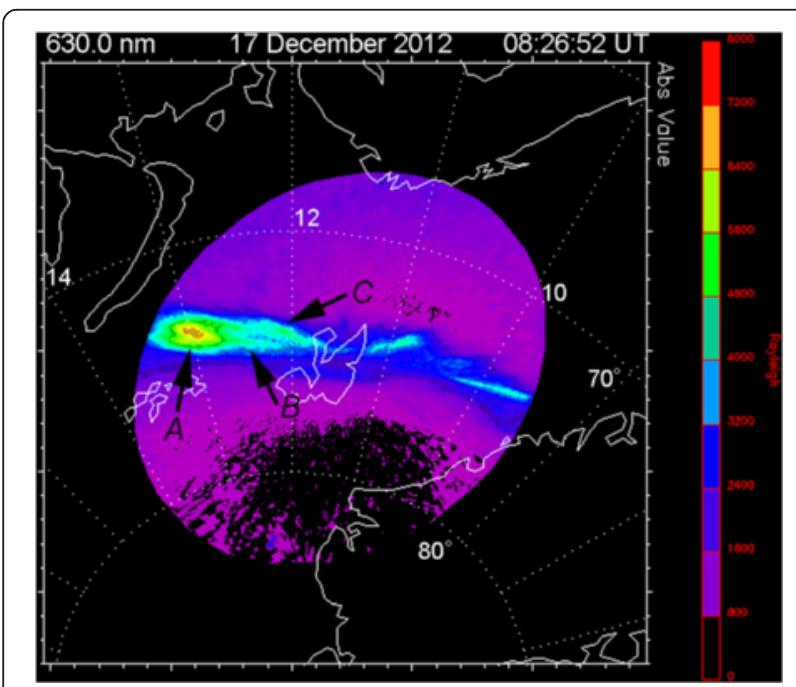

Figure 1 A 630.0 nm dayside all-sky image taken at 08:26:52 UT on 17 December 2012. The all-sky image is projected onto an Earth-centered sphere at a height of $250 \mathrm{~km}$ with the geomagnetic coordinate system shown in the background. Black arrows indicate three auroral structures: $A, B$, and $C$. exhibited enhanced emission (exceeding $4 \mathrm{kR}$, greenish color), three distinct areas of which are indicated by black arrows in Figure 1. The largest region, which occurred at approximately 13:00 MLT, is hereafter referred to as Aurora $A$. The smaller auroral structure located adjacent to Aurora $A$ is called Aurora $B$. The auroral structure located equatorward of Aurora $B$ is referred to as Aurora $C$. This study focuses on Auroras $B$ and $C$.

Figure 2 shows the solar wind conditions from 07:30 to 09:30 UT. Solar wind data obtained by the Advanced Composition Explorer (ACE) spacecraft positioned approximately $230 R_{\mathrm{E}}$ upstream in the solar wind are represented by solid black lines, and the $15 \mathrm{~s}$ averaged IMF data from the GEOTAIL satellite, which was located at $\left(X_{\mathrm{GSE}}\right.$, $\left.Y_{\mathrm{GSE}}, Z_{\mathrm{GSE}}\right)=(23.7$ to $23.3,17.4$ to $18.3,5.1$ to 5.5$) R_{\mathrm{E}}$ in

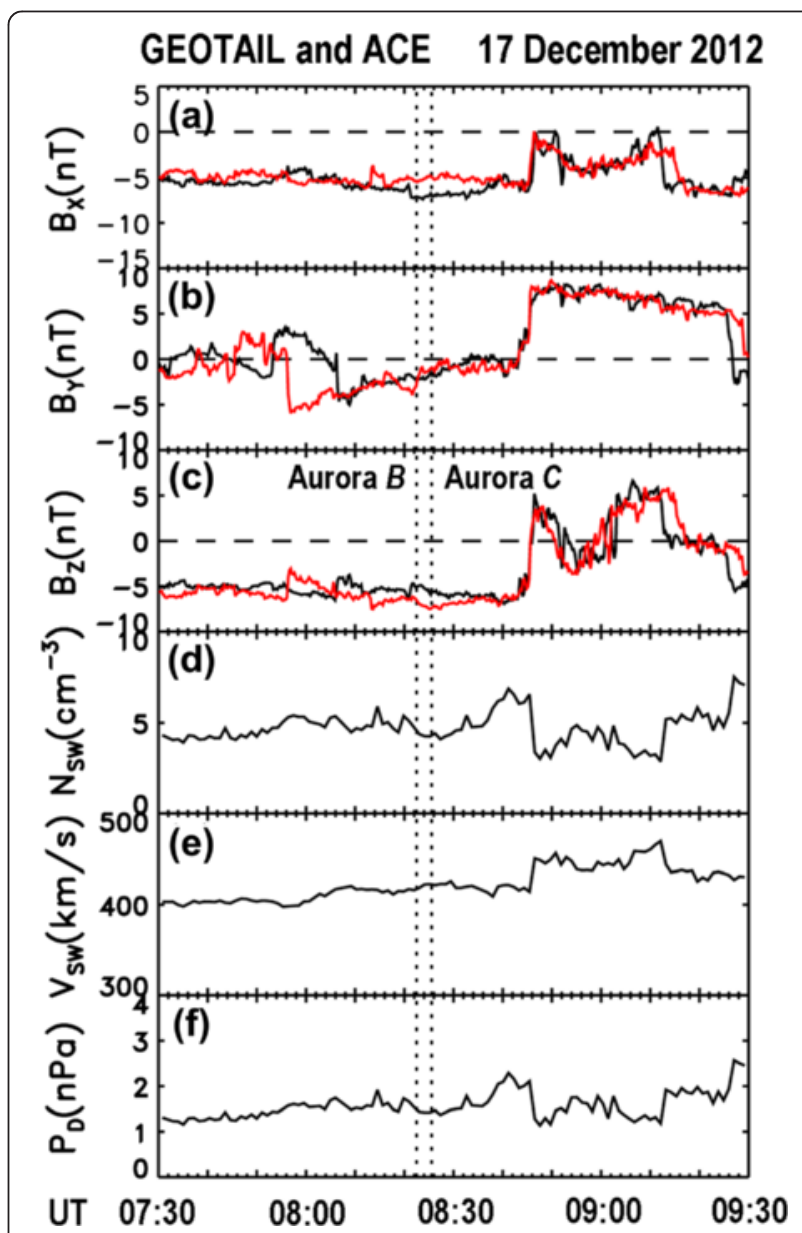

Figure 2 GEOTAIL (red) and ACE (black) solar wind conditions. The data from GEOTAIL in the near-Earth solar wind are advanced by 7 min, whereas those from ACE, located approximately $230 R_{E}$ upstream in the solar wind, are delayed by $47 \mathrm{~min}$. The (a) $X$-, (b) $Y$-, and (c) Z-components of the IMF in the geocentric solar magnetospheric coordinate, (d) the solar wind proton density, (e) the flow speed, and (f) the dynamic pressure are plotted. The two dotted lines indicate the time when Auroras $B$ and $C$ appeared in the dayside ionosphere. 
the geocentric solar ecliptic (GSE) coordinate system, are plotted in the top three panels (Figure 2a,b,c) as red lines. Figure 2a,b,c shows the $X$-, $Y$-, and $Z$-components, respectively, of the IMF in the geocentric solar magnetospheric (GSM) coordinate system. In these figures, the GEOTAIL data are advanced by $7 \mathrm{~min}$.

To estimate this time lag, we used (Lockwood et al. 1989)

$$
\begin{aligned}
T_{\text {delay }}= & \left\{X_{S C}-1.33 X_{M P}-Y_{S C}\left(\frac{B_{X}}{B_{Y}}\right)+2.64 X_{M P}\right\} \\
& V_{S W}^{-1}+2(\min ),
\end{aligned}
$$

where $X_{\mathrm{SC}}$ and $Y_{\mathrm{SC}}$ represent the spacecraft position in the GSE coordinate system, $X_{\mathrm{MP}}$ is the magnetopause location, $B_{\mathrm{X}}$ and $B_{\mathrm{Y}}$ are the $X$ - and $Y$-components of the IMF in the GSE coordinate system, and $V_{\mathrm{SW}}$ is the solar wind speed. The second term on the right-hand side, $1.33 X_{\mathrm{MB}}$ represents an approximation of the subsolar standoff distance of the bow shock (Fairfield 1971). The factor of 2.64 in the fourth term comes from the multiplication of 0.33 and 8 , where 8 is the slowdown factor of the solar wind in the subsolar magnetosheath (Spreiter and Stahara 1980; Khan and Cowley 1999). The last term, $2 \mathrm{~min}$, represents the Alfven wave travel time from the magnetopause to the ionosphere. We assumed $X_{\mathrm{MP}}$ to be $10 R_{\mathrm{E}}$ and obtained $T_{\text {delay }}=-7 \mathrm{~min}$ by using $\left(X_{\mathrm{SC}}, Y_{\mathrm{SC}}\right)=(23.5,17.8) R_{\mathrm{E}}$ and $\left(B_{\mathrm{X}}, B_{\mathrm{Y}}\right)=(-5.2,-1.3) \mathrm{nT}$ as average values for $08: 20$ to $08: 30 \mathrm{UT}$ and taking $V_{\mathrm{SW}}$ to be $410 \mathrm{~km} \mathrm{~s}^{-1}$ from the ACE data.

The ACE data (black line) plotted in Figure 2 are 16 and $64 \mathrm{~s}$ averages of IMF and plasma data, respectively. A delay of $47 \mathrm{~min}$ was introduced in the ACE data to align the sharp increase in the ACE $B_{Z}$ with a similar increase in the GEOTAIL $B_{\mathrm{Z}}$ at approximately 08:45 UT. The two dotted lines indicate the time at which the aurora images of Auroras $B$ and $C$ (Figure 1) were first captured, specifically 08:22:28 and 08:25:33 UT, respectively. The aurora images will be shown later. As is shown in both spacecraft data, the IMF $B_{\mathrm{Z}}$ was very stable at approximately $-5 \mathrm{nT}$ (Figure 2c) during the interval of approximately $1 \mathrm{~h}$ before the appearance of the auroral structures.

The GEOTAIL IMF data (red line) indicate that Aurora $B$ appeared when $\left(B_{\mathrm{Y}}, B_{\mathrm{Z}}\right)$ was approximately $(-4,-6) \mathrm{nT}$. Immediately following this, the IMF turned further southward, and when $\left(B_{\mathrm{Y}}, B_{\mathrm{Z}}\right)$ was approximately $(-2,-7) \mathrm{nT}$, Aurora $C$ appeared. As is shown later, the motion of Aurora $C$ had a smaller eastward component than that of Aurora $B$, which is consistent with these IMF values.

The $X$-component $B_{\mathrm{X}}$ of the GEOTAIL IMF was relatively constant during the interval of approximately $1 \mathrm{~h}$ before the appearance of the auroral structures of interest (Figure 2a). A negative $B_{\mathrm{X}}$ when $B_{\mathrm{Z}}<0$ may be a relatively favorable condition for stronger auroral emission on the dayside (Yang et al. 2013). The solar wind plasma density $N_{\mathrm{sw}}$ was approximately $5 \mathrm{~cm}^{-3}$ during that interval (Figure 2d). The solar wind speed $V_{\mathrm{sw}}$ and the dynamic pressure $P_{\mathrm{D}}$ were also stable at approximately $410 \mathrm{~km} \mathrm{~s}^{-1}$ (Figure 2e) and in the range of approximately 1 to $2 \mathrm{nPa}$ (Figure 2f), respectively.

\section{Particle observations from the DMSP spacecraft}

Figure 3 shows the data from the particle spectrometers on the DMSP F18 satellite from 08:18 to 08:28 UT on 17 December 2012, during which DMSP F18 flew from the dusk to the prenoon sector. The energy fluxes of the electrons and ions are plotted with color codes in the bottom two panels, together with the integral energy flux and average energy of the electrons and ions. Note that the ion energy axis is inverted in the fourth panel. The DMSP satellite initially measured regions on the dusk side from 08:19:15 to 08:20:00 UT, during which the energy flux of the electron precipitation (third panel) was relatively low and the ion precipitation (fourth panel) had a relatively high energy (the so-called central plasma sheet). The spacecraft entered the boundary plasma sheet at approximately 08:20:00 UT; here, the energy of the peak electron energy flux exceeded $1 \mathrm{keV}$, indicating that the precipitating electrons had accelerated fluxes. The high-latitude portion of this boundary plasma sheet appears to be smoothly connected to the region where the electron energy flux was very low (after approximately 08:22:30 UT).

At approximately 08:25:15 UT, the spacecraft entered the ion precipitation region that is typical for the cusp. Specifically, precipitating ions with energies between 100 $\mathrm{eV}$ and $1 \mathrm{keV}$ became evident at 08:25:18 UT, i.e., 75.50 magnetic latitude (MLAT) and 13:33 MLT. The total energy flux and average energy of the ions generally increased with decreasing latitude (first and second panels, red dots) until 08:27 UT. After that, the energy flux became somewhat low (top panel, red dots). After 08:27:14 $\mathrm{UT}$, the ion energy flux in the range of 1 to $10 \mathrm{keV}$ (fourth panel) was lower than $1 \times 10^{6} \mathrm{eV} \mathrm{cm}^{-2} \mathrm{~s}^{-1} \mathrm{sr}^{-1} \mathrm{eV}^{-1}$ (becoming a greenish color). We determined this latitude ( $72.54^{\circ}$ MLAT) to be the equatorward boundary of the cusp. The cusp range is represented by the red horizontal bar between the two spectrograms. Presumably, the region equatorward of this range is on a closed field line because the energy flux of the precipitating electrons at approximately $100 \mathrm{eV}$ (i.e., electrons of magnetosheath origin) is very low. As will be shown in the following section, the most notable result is that the cusp includes the region containing precipitating electrons with a higher energy flux (reddish color in the third panel). 


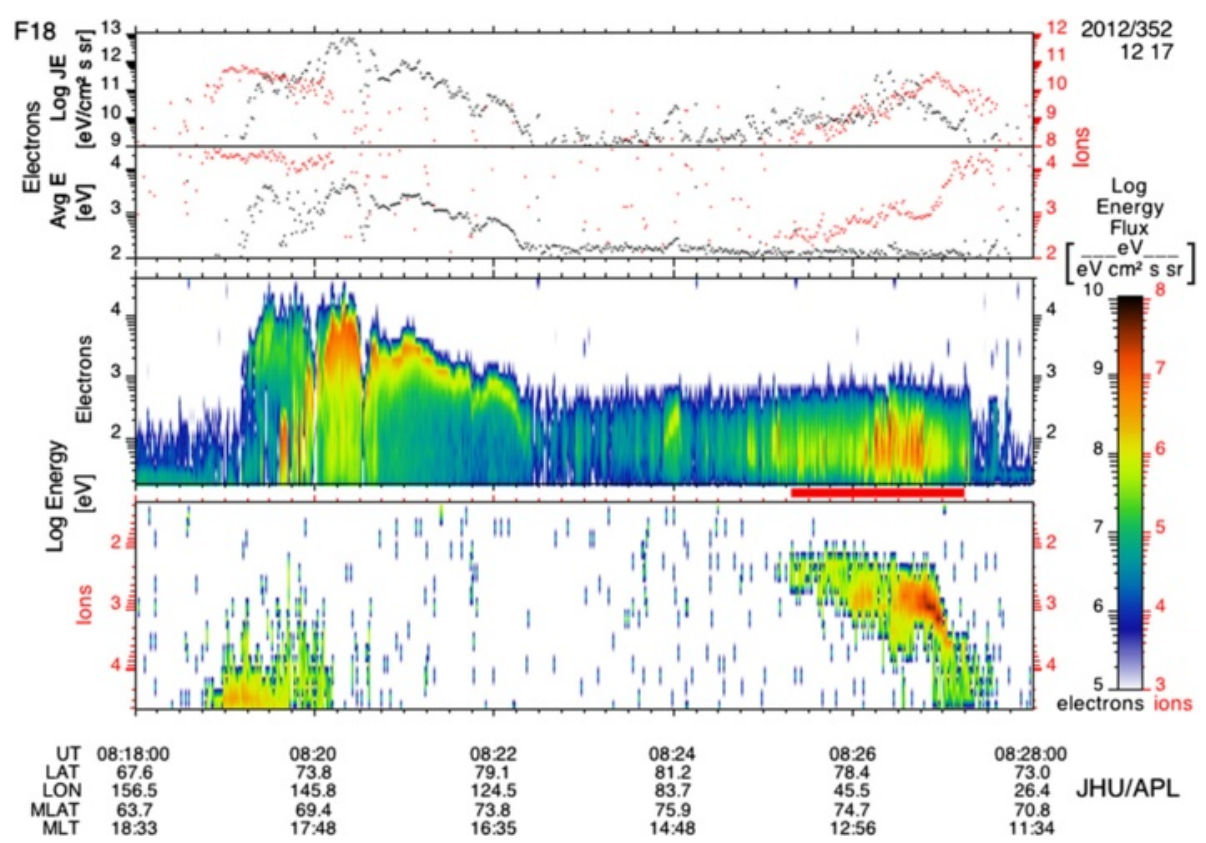

Figure 3 DMSP F18 particle observations along the passage from the dusk to the prenoon sector. The top panel indicates the electron and ion integral energy fluxes, and the second panel shows the average energy. The bottom two panels present the electron and ion differential energy flux spectrograms. The red horizontal bar, which extends from $75.50^{\circ}$ to $72.54^{\circ} \mathrm{MLAT}$, indicates the region we defined as the cusp.

\section{Results and discussion}

\section{Multiple boundary crossings inside the cusp}

Figure 4 presents an expanded plot of the DMSP F18 particle data (shown in Figure 3) near the electron precipitation with very high flux. Figure 4a shows the ratio of the integral ion number flux to the integral electron number flux in a logarithmic scale. To obtain this ratio, we first calculated the integral number flux $\left(J_{\text {Tот }}\right)$ by dividing the integral energy flux (JE, shown in the top panel of Figure 3$)$ by the average energy $\left(E_{\mathrm{Avg}}\right.$, shown in

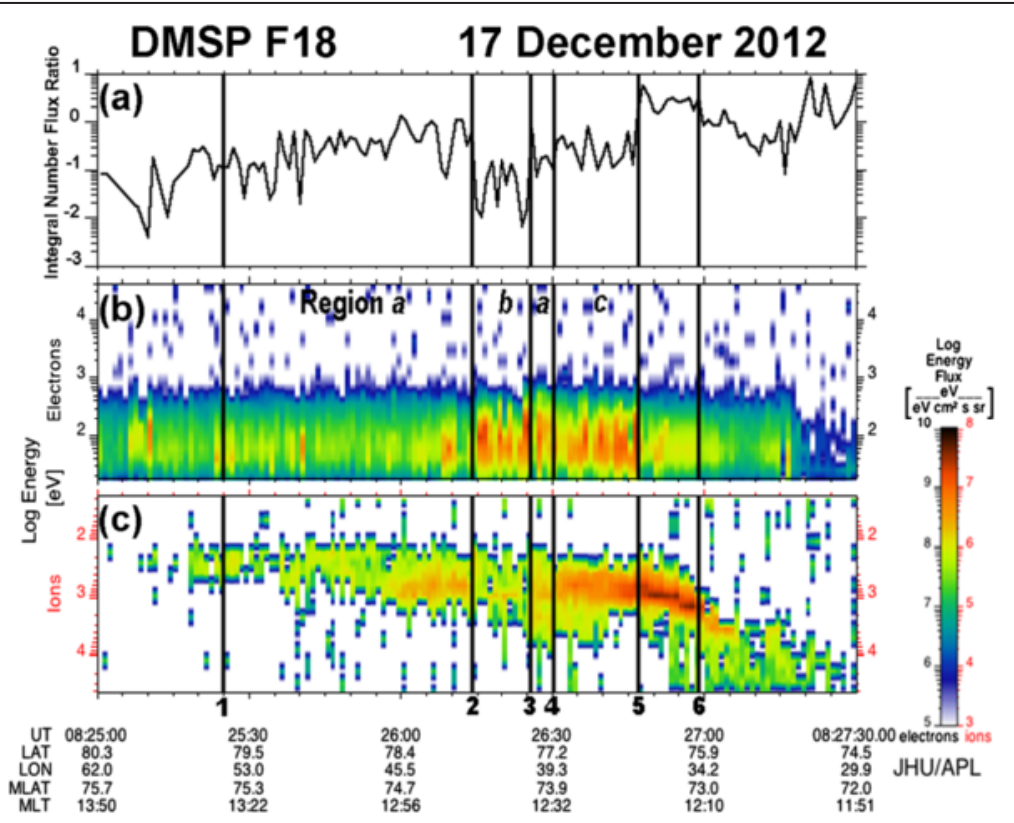

Figure 4 Particle data from DMSP F18 near the electron precipitation with a very high flux. The top panel (a) represents the normalized ratio of the integral ion number flux to the integral electron number flux in a logarithmic scale. The format of the bottom two panels $(\mathbf{b}, \mathbf{c})$ is the same as that of the bottom two panels of Figure 3. The six vertical lines in each panel indicate the boundaries between different particle features. 
the second panel of Figure 3) for the electrons and ions (Hardy et al. 1985). We then defined the ratio as

$$
R=\left(\frac{1}{k}\right) \frac{J_{T O T(i o n)}}{J_{T O T(\text { elec })}}
$$

where $k$ is constant and was determined to be 0.057 . This is a normalization factor so that $R$ can be roughly between $10^{-2}$ and 10 . We obtained 0.057 from the median of the ratio $J_{\text {TOT(ion) }} / J_{\text {TOT(elec) }}$ in the region 08:26:48 to $08: 27: 16 \mathrm{UT}$, which is on the equatorward side of the high-flux region, i.e., outside of the region of focus in this paper. This means that $R$ is normalized by the features in the steady cusp. Note that the choice of $k$ would not affect the main results of this paper.

Figure 4 shows the boundaries between different precipitating plasma features. Boundary 1, which is the leftmost line of the six lines on the plot, is the position over which the DMSP satellite flew at 08:25:25 UT. In the electron spectrogram (Figure 4b), this boundary represents the point where the maximum energy flux for the three energy steps around $100 \mathrm{eV}$ first exceeded $1 \times 10^{8}$ $\mathrm{eV} \mathrm{cm}{ }^{-2} \mathrm{~s}^{-1} \mathrm{sr}^{-1} \mathrm{eV}^{-1}$ (yellow color) for two consecutive seconds. This point occurred at (MLAT, MLT $)=\left(75.4^{\circ}\right.$, 13:26). These two consecutive data bins, i.e., the observations over the given $2 \mathrm{~s}$, corresponded to a horizontal scale of approximately $15 \mathrm{~km}$ along the satellite path. An aurora of this horizontal size would be detected over an area larger than $2 \times 2$ pixels (out of $512 \times 512$ pixels) wherever the aurora is situated inside the imager's field of view. The $2 \times 2$ pixel area is the smallest that can be reasonably resolved. Boundary 1 was very close to the poleward boundary of the cusp ion precipitation (08:25:18 UT), which was defined using the ion precipitation in Figure 3.

Boundary 2 is located at the position the DMSP satellite crossed at 08:26:14 UT; at this position, (MLAT, MLT $)=\left(74.37^{\circ}, 12: 44\right)$. This boundary was determined from the sharp drop in the integral number flux ratio (Figure 4a). This can also be seen as a sharp drop in the ion energy, as at this time, the energy of the peak ion energy flux dropped to approximately $200 \mathrm{eV}$ with a decrease in the ion energy flux (Figure 4c). After this time, low-energy ion precipitation appeared intermittently. Just $1 \mathrm{~s}$ later, i.e., at 08:26:15 UT, the satellite entered the region where the energy flux of the electron precipitation was very high; the maximum of the energy flux for the three energy bins around $100 \mathrm{eV}$ exceeded $1 \times 10^{9}$ $\mathrm{eV} \mathrm{cm}{ }^{-2} \mathrm{~s}^{-1} \mathrm{sr}^{-1} \mathrm{eV}^{-1}$. We refer to the region before Boundary 2 and after Boundary 1 as Region $a$.

The next boundary, Boundary 3, was chosen as the position the DMSP satellite crossed at 08:26:26 UT; at Boundary $3,($ MLAT, MLT $)=\left(74.05^{\circ}, 12: 35\right)$. At this time, there was a significant jump in the integral number flux ratio (Figure 4a). The maximum electron energy flux from the three energy bins around $100 \mathrm{eV}$ decreased to values below $1 \times 10^{8} \mathrm{eV} \mathrm{cm}^{-2} \mathrm{~s}^{-1} \mathrm{sr}^{-1} \mathrm{eV}^{-1}$, similar to the values often observed prior to Boundary 2. In addition, at this time, the energy flux of the ion precipitation sharply increased and approached that observed before Boundary 2 . We refer to the region between Boundaries 2 and 3 as Region $b$. Region $b$ is characterized as the region where the integral ion number flux relative to the integral electron number flux is very low compared with Region $a$.

After 08:26:26 UT (Boundary 3), ion precipitation with features similar to those seen in Region $a$ appeared and continued for a brief period of time. At 08:26:30 UT, the energy of the peak ion energy flux dropped to well below $1 \mathrm{keV}$. We designated this position Boundary 4. The electron features in the region between Boundaries 3 and 4 are similar to those near the equatorward edge of Region $a$, i.e., the region observed during 08:26:08 to 08:26:10 UT. As was mentioned above, the electron energy flux dropped sharply at Boundary 3, and that low value is also similar to the values that were often observed prior to Boundary 2. The integral number flux ratios between Boundaries 3 and 4 are also similar to the ratios prior to Boundary 2. We thus regarded the region between Boundaries 3 and 4 as a reappearance of Region $a$.

For a while after 08:26:30 UT (Boundary 4), the satellite continued to observe high electron energy flux. These electron features are very similar to those seen in Region $b$. However, there is a clear difference in the ion precipitation features. The energy flux of the ions was higher after Boundary 4 than in Region $b$. The integral number flux ratio was also higher after Boundary 4 than in Region $b$. These observations are crucial results of this study and will be used later for comparison with the auroral image. At 08:26:47 UT, the integral number flux ratio increased sharply, and the maximum energy flux of the electron precipitation for the three energy bins around $100 \mathrm{eV}$ no longer reached $1 \times 10^{9} \mathrm{eV} \mathrm{cm}^{-2} \mathrm{~s}^{-1} \mathrm{sr}^{-1} \mathrm{eV}^{-1}$. We designated this position Boundary 5 , and we refer to the region between Boundaries 4 and 5 as Region $c$.

Although the energy flux of the electron precipitation shows a sharp drop at Boundary 5 , this flux remained relatively high for a while longer. Boundary 6 (at 08:26:58 UT) was determined to be the last point of that relatively highflux period. After this boundary, there were no further instances of the maximum energy flux for the three energy bins with two consecutive values exceeding $1 \times 10^{8} \mathrm{eV} \mathrm{cm}^{-2}$ $\mathrm{s}^{-1} \mathrm{sr}^{-1} \mathrm{eV}^{-1}$. At this boundary, (MLAT, MLT) $=\left(73.08^{\circ}\right.$, 12:12); this latitude was higher than the equatorward boundary of the cusp $\left(72.54^{\circ}\right)$ by approximately $0.5^{\circ}$.

\section{Electron precipitation for each auroral structure}

Figures 5 and 6 show how these six boundaries are situated relative to the moving cusp aurora. Figure 5a shows the position of Boundary 1 (red square) on the $630.0 \mathrm{~nm}$ all-sky image taken at 08:25:33 UT, which was $8 \mathrm{~s}$ after 


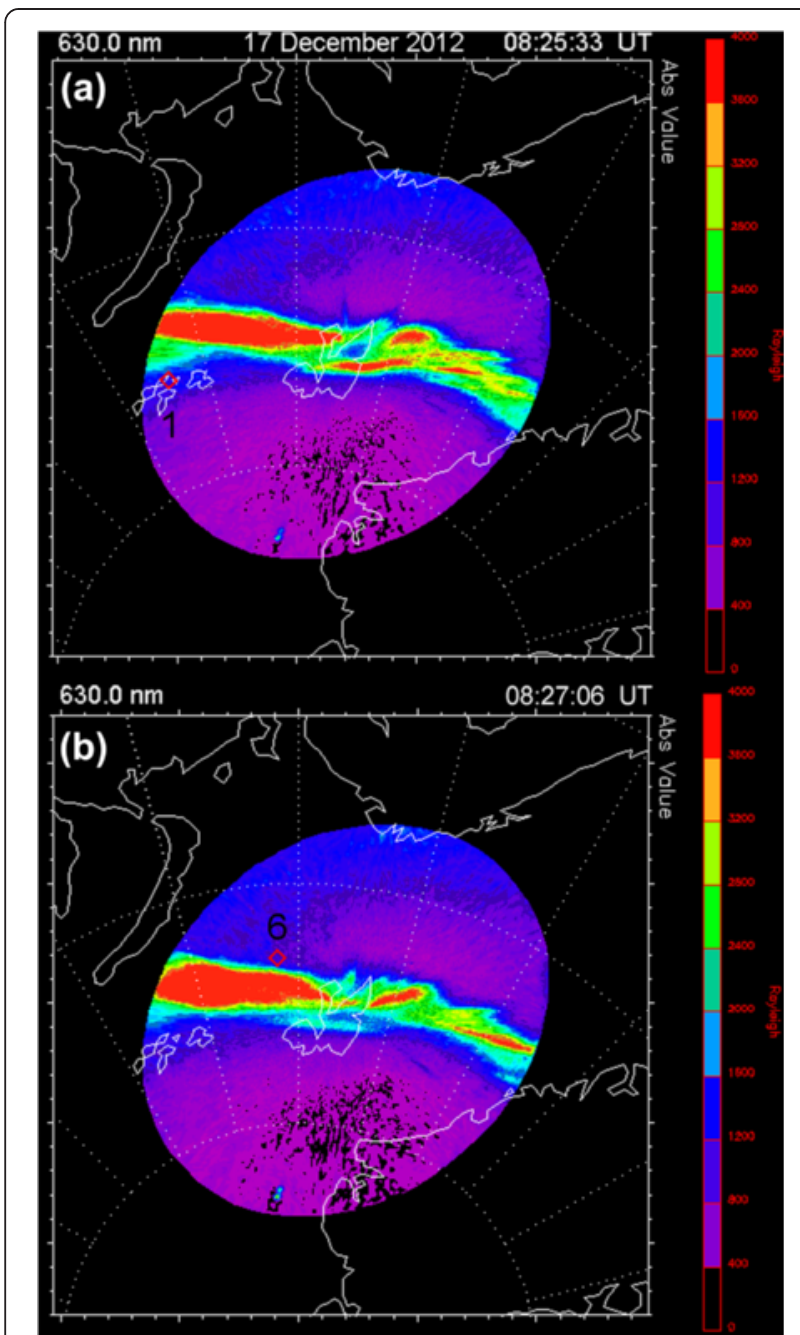

Figure 5 Positions of (a) Boundary 1 and (b) Boundary 6 relative to the $630.0 \mathrm{~nm}$ oval. The positions are indicated by red diamonds.

the satellite passed through Boundary 1 . Boundary 1 is located near the poleward boundary of the dayside 630 $\mathrm{nm}$ auroral oval, whose emission ranged over 0.8 to $1.6 \mathrm{kR}$ (dark blue in Figure 5a). The $630 \mathrm{~nm}$ emission is produced by the deexcitation of the ${ }^{1} D$ state of atomic oxygen, a state with a theoretical lifetime of $110 \mathrm{~s}$. Considering this lifetime, we checked all auroral images obtained between 08:25:25 and 08:27:15 UT (=08:25:25 + 110 s). The position of Boundary 1 relative to the poleward boundary of the $630 \mathrm{~nm}$ auroral oval was very similar throughout this interval.

Figure $5 \mathrm{~b}$ shows the position of Boundary 6 (red square) on the $630.0 \mathrm{~nm}$ all-sky image taken at 08:27:06 UT, which was $8 \mathrm{~s}$ after the satellite passed through Boundary 6 at 08:26:58 UT. Boundary 6 was located near the equatorward boundary of the $630 \mathrm{~nm}$ dayside auroral oval. This provides clear evidence that the cusp aurora, including its equatorward part, is located in the open field line region,

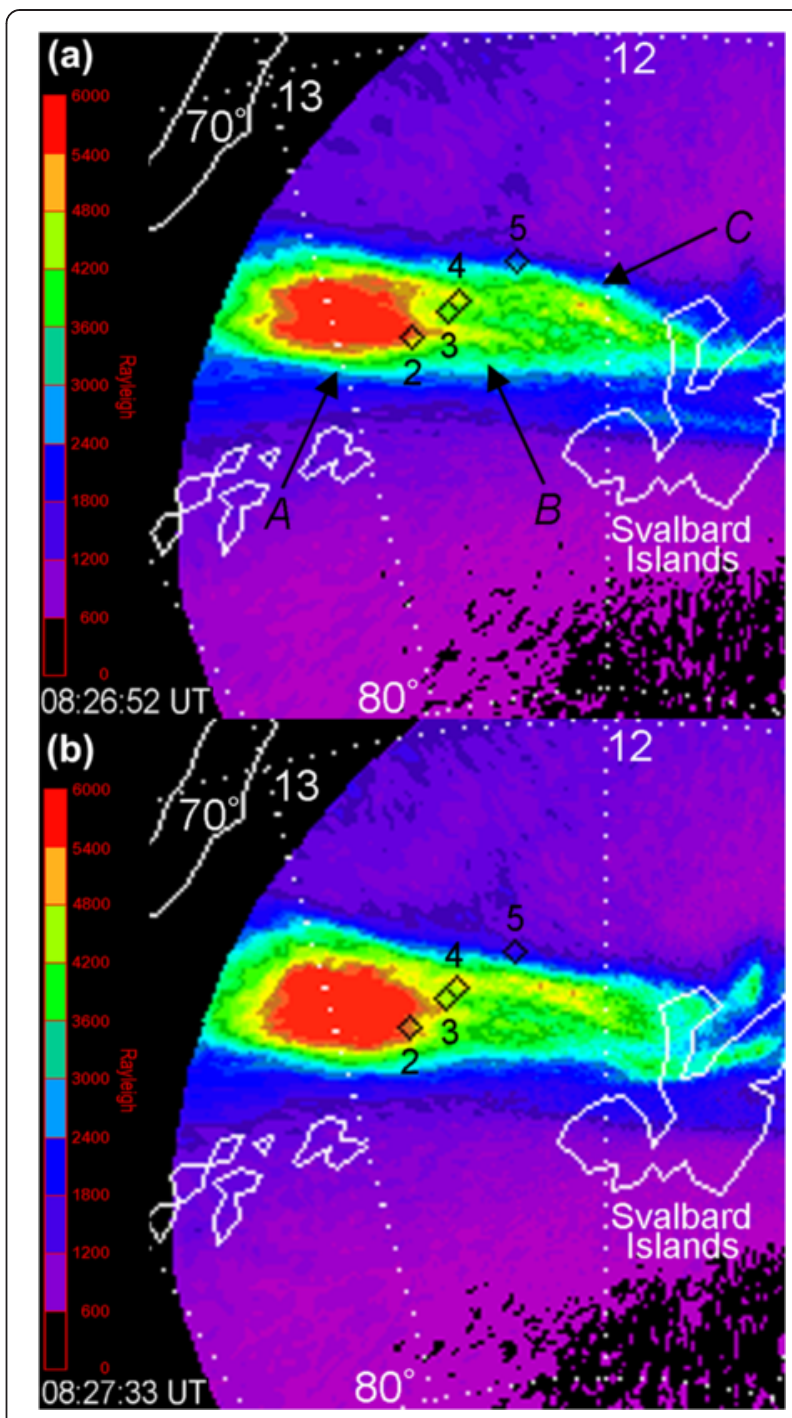

Figure 6 Positions of four boundaries (black diamonds) relative to Auroras $A, B$, and $C$. The four boundaries are shown on the $630.0 \mathrm{~nm}$ images taken at (a) 08:26:52 and (b) 08:27:33 UT.

though this feature has already been suggested with HF radar and a meridian-scanning photometer by Milan et al. (1999). We checked all auroral images obtained between 08:26:58 and 08:28:48 UT $(=08: 26: 58+110 \mathrm{~s})$. The position of Boundary 6 relative to the equatorward boundary of the $630 \mathrm{~nm}$ auroral oval was very similar throughout this interval.

Figure 6a shows the positions of Boundaries 2, 3, 4, and 5 on the $630.0 \mathrm{~nm}$ all-sky image taken at 08:26:52 UT, which was also shown in Figure 1. This time is 38, 26, 22, and $5 \mathrm{~s}$ after the detection of Boundaries 2, 3, 4, and 5, respectively. As indicated in Figure 6a, the region between Boundaries 2 and 3 (Region $b$ in Figure 4) overlapped Aurora $B$, and the region between Boundaries 4 and 5 (Region $c$ in Figure 4) overlapped the eastward part of Aurora $C$. As will be shown later, Aurora $B$ was 
moving eastward, whereas Aurora $C$ did not move substantially at that time. Subsequently obtained images also show that the poleward and equatorward boundaries of Aurora $C$ were Boundaries 4 and 5 , respectively. Figure 6b, taken at 08:27:33 UT, is an example of such an image. This image was taken $46 \mathrm{~s}$ after the DMSP observation of Boundary 5. At this time, Aurora $C$ was still situated between Boundaries 4 and 5 . Note that because the excited oxygen atom has a relatively long lifetime (theoretically $110 \mathrm{~s}$, as mentioned above), obtaining a more precise relationship between the extent of the moving auroral structure and the electron precipitation region would require information about how the neutral wind, with which the excited oxygen atom moves, was distributed during that period of time.

Figure 4 shows that the particle precipitation features between Boundaries 3 and 4 were similar to those in regions at latitudes higher than Boundary 2. We know from Figure $6 \mathrm{a}$ that both regions were parts of Aurora $A$. These spatial relationships, i.e., Aurora $A$-Region $a$, Aurora $B$-Region $b$, and Aurora $C$-Region $c$ are shown schematically in Figure 7, together with Boundaries 2, 3, 4 , and 5. Note that the satellite just skimmed Aurora $A$ without crossing through its main part. This is why the DMSP observation obtained before Boundary 2 did not include regions where the energy flux of the electron precipitation was very high (Figure 4). Figure 4 also shows that the energy flux of the electron precipitation was very low both immediately before Boundary 2 and just after Boundary 3. Figure 6 implies that those regions may be connected as the outer edge of Aurora $A$.

\section{Change in the positions of Auroras $B$ and $C$}

From Figure 4, we have shown that Regions $b$ and $c$ had significantly different ion precipitation features, whereas their electron precipitation features were very similar. In this section, we will show that this difference in ion precipitation is reasonable when considering the motion of Regions $b$ (i.e., Aurora $B$ ) and $c$ (i.e., Aurora $C$ ). Figure 8 shows when and where Auroras $B$ and $C$ appeared and

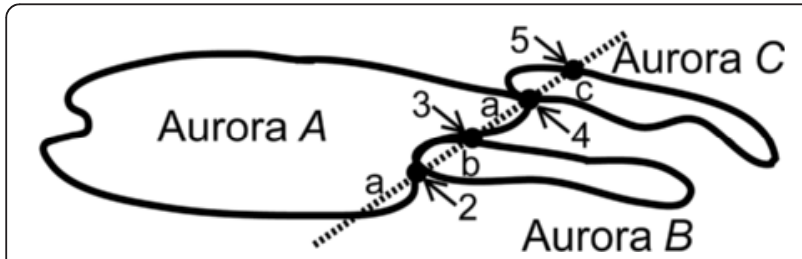

Figure 7 Schematics of the spatial relation between the plasma boundaries and the three auroral structures. The dotted line represents the DMSP F18 pass. Boundaries 2, 3, 4, and 5, which were determined from the DMSP data (Figure 4), are plotted as black dots on the line. Regions $a, b$, and $c$, which are indicated within the auroral region, are also based on the DMSP data (Figure 4). how they moved. Figure 8a (top left) shows the auroral image at 08:22:15 UT; the three white dotted lines indicate 11:00, 12:00, and 13:00 MLT. When the image at 08:22:28 UT (Figure 8b) is compared with this image, a faint intensification, indicated by a black arrow, can be seen in the image at 08:22:28 UT. The location of the peak emission is (MLAT, MLT) $=\left(74.3^{\circ}, 11: 56\right)$. The aurora was not conspicuous at this time but became clear in the image shown in Figure 8c, which was taken $47 \mathrm{~s}$ after the image in Figure $8 \mathrm{~b}$.

As shown by the black arrow in each of the subsequent images, this auroral structure moved slightly poleward until 08:25:53 UT (Figure 8i) and then accelerated strongly eastward, which is consistent with the motion of the reconnected field line for a negative IMF $B_{\mathrm{Y}}$ (Figure 2). The image shown in Figure $8 \mathrm{k}$ is from the same data source as those shown in Figures 1 and 6a. The location of Aurora $B$ at 08:27:19 UT (Figure 8l) is (MLAT, $\operatorname{MLT})=\left(74.5^{\circ}, 12: 24\right)$. We determined this location from the trailing edge of the aurora whose emission is more than $4 \mathrm{kR}$. The DMSP observation of Region $b$ (i.e., 08:26:14 UT for Boundary 2) was obtained in the middle of the eastward motion of the aurora and approximately $230 \mathrm{~s}$ after the appearance of Aurora B. After 08:27:19 UT (Figure 8l), Aurora $B$ was no longer evident, and thus the observation by the spacecraft at 08:26:14 UT was obtained just before Aurora $B$ disappeared, i.e., in the final stage of the aurora.

The motion of Aurora $B$ suggests that it takes a few minutes (from 08:22:28 to 08:25:53 UT) for the result of the tension exerted by the reconnected field line to become prominent in the ionosphere after the appearance of the cusp aurora. A similar tendency can be identified in a larger eastward-moving auroral structure, which was seen over the mainland of the Svalbard Islands (Figure 8f,g,h,i,j,k). During the interval shown in Figure 8f,g,h,i,j,k, the auroral structure was moving eastward, but prior to that (Figure $8 \mathrm{~d}, \mathrm{e}$ ), the auroral structure had been moving poleward, roughly along the 1100 MLT meridian. A recent study based on simultaneous observations from the Super Dual Auroral Radar Network (SuperDARN), a farultraviolet instrument on the IMAGE spacecraft, and a ground magnetometer also reported similar flow features for the cusp proton aurora event (Taguchi et al. 2010).

The red arrow in Figure 8h (08:25:33 UT) indicates the initial image of Aurora $C$. The location of the peak emission is (MLAT, MLT) $=\left(74.2^{\circ}, 12: 08\right)$. This aurora did not move substantially until 08:27:19 UT (Figure 81) but later moved poleward. The all-sky images obtained 3 min later (i.e., at 08:30:19 UT) are shown in Figure 9. The location of Aurora $C$ is approximately (MLAT, $\operatorname{MLT})=\left(75.3^{\circ}, 12: 15\right)$. As is expected from a negative value of the IMF component $B_{\mathrm{Y}}$, the motion had an eastward component as well as a poleward component. After this time, Aurora $C$ continued to move further poleward and 


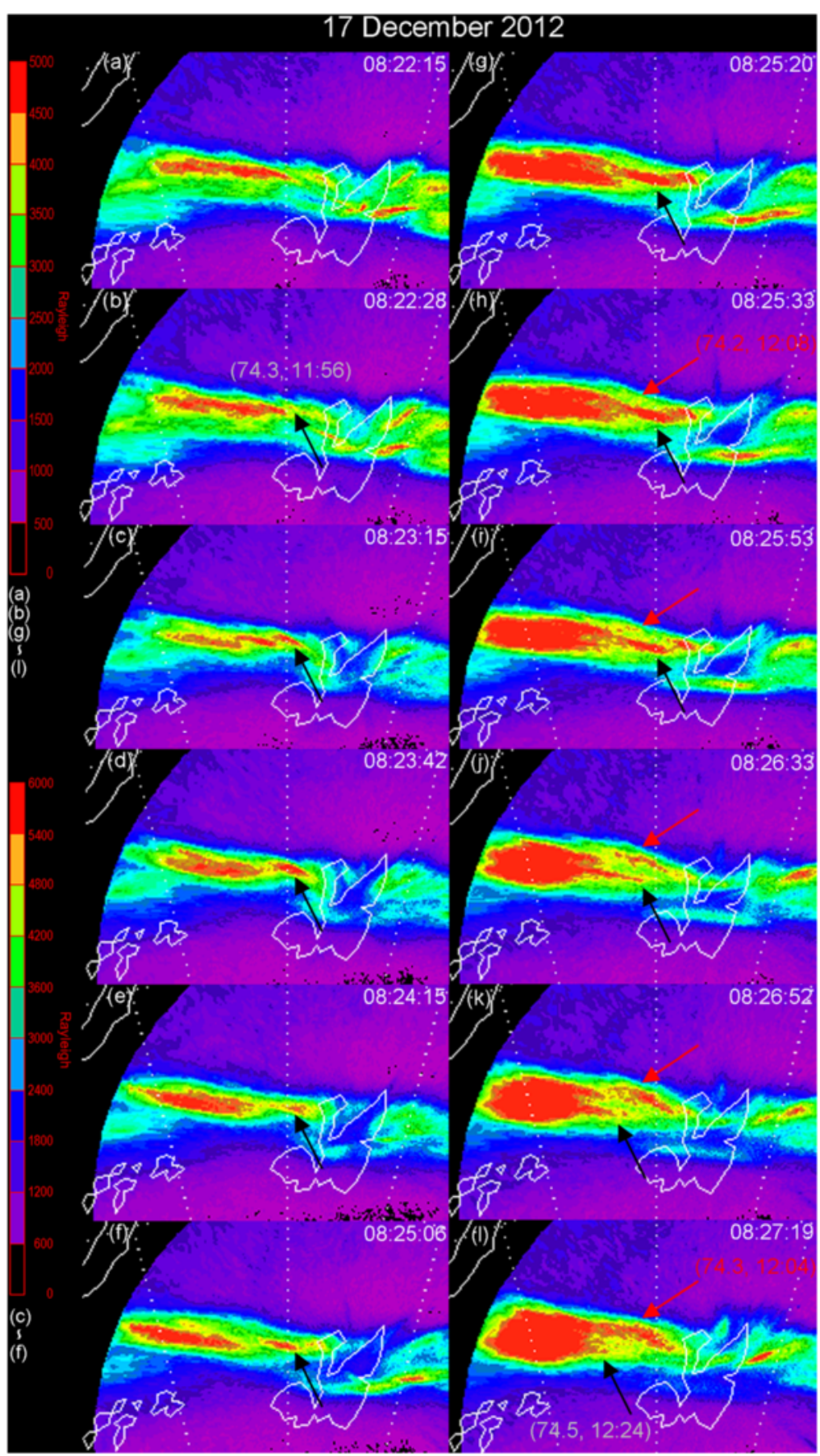

Figure 8 Changes in the positions of Auroras $B$ and C. The image in (a) represents the situation before the appearance of Aurora B and Aurora C. The black arrow in (b)-(l) indicates the position of Aurora B, and the red arrow, shown in (h)-(l), represents the position of Aurora C. In (b), (h), and (l), the location of the aurora is given as coordinates (MLAT, MLT). The image in $(\mathbf{k})$ has the same source as the images in Figures 1 and 6 , but the color coding is different.

disappeared after 08:33:18 UT (not shown). The lifetime exceeded $465 \mathrm{~s}$. The DMSP observation of Region $c$ at 08:26:30 UT (i.e., Boundary 4) was obtained approximately $60 \mathrm{~s}$ after its appearance, i.e., in the early stage of the aurora.

The interval between the appearance of Aurora $C$ and the DMSP observation (60 s) is short when compared with the interval for Aurora $B$, which was approximately $230 \mathrm{~s}$. We have shown that the energy flux of the ion precipitation in Aurora $C$ was much higher than that in Aurora $B$. We know that the energy flux of the precipitating ions in the young open flux tube (i.e., Aurora $C$ ) was much higher than in the old open flux tube (i.e., Aurora $B)$. This is consistent with the signatures expected from 


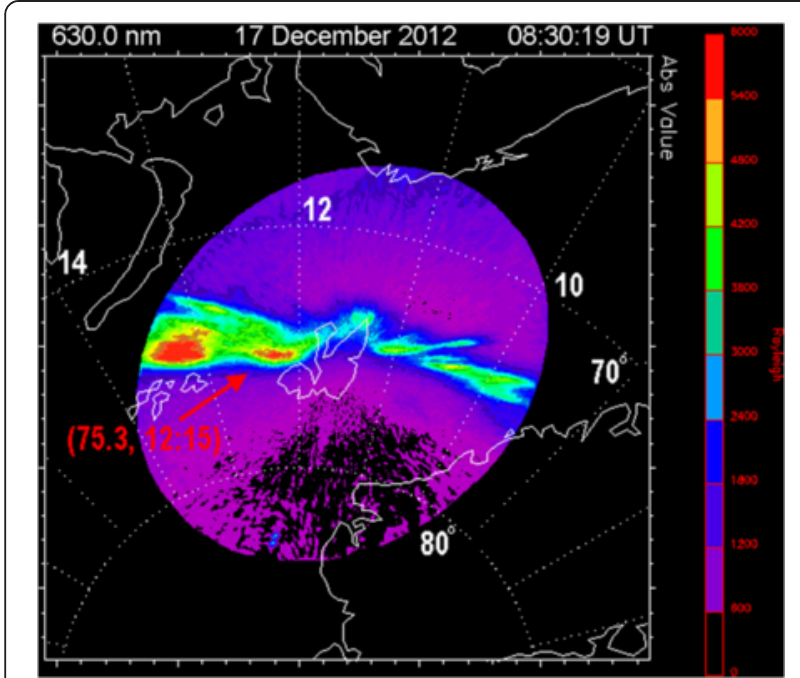

Figure 9 A $630.0 \mathrm{~nm}$ dayside all-sky image taken at 08:30:19 UT on 17 December 2012. The format is the same as that of Figure 1. The red arrow indicates Aurora C.

reconnection, indicating that the energy flux of the ion precipitation tends to decrease with increasing distance from the footprint of the reconnection point (e.g., Onsager et al. 1993).

\section{High-flux electron precipitation}

The high fluxes of the electron precipitation in both $\mathrm{Re}$ gions $b$ and $c$ suggest that the energy fluxes of the precipitating electrons in the young and old open flux tubes do not differ significantly. For the present event, the maximum differential energy flux at approximately 100 $\mathrm{eV}$ similarly exceeded $1 \times 10^{9} \mathrm{eV} \mathrm{cm}^{-2} \mathrm{~s}^{-1} \mathrm{sr}^{-1} \mathrm{eV}^{-1}$ in both regions. In contrast, as mentioned above, the energy fluxes of the precipitating ions in those regions differed significantly. Thus, it appears that the electron precipitation flux level is controlled by a mechanism independent of the ion precipitation flux.

Further studies are needed to understand the process that directly produces the high electron precipitation flux inside an open flux tube; however, it is estimated that an upward field-aligned current whose carrier is the precipitating electrons and a parallel potential drop, which is presumably produced in conjunction with the upward field-aligned current, may be important factors. A mesoscale convection system consisting of upward and downward field-aligned currents was proposed for the ionospheric signatures of the FTE by Southwood (1987); subsequently, Oksavik et al. (2004) showed that such a flow pattern actually exists. Collocation of the mesoscale upward field-aligned current with intense electron precipitation can be seen in an event reported by Taguchi et al. (1993) (e.g., 02:51:32 to 02:51:40 UT in Plate 1 of that work). Using simultaneous satellite observations of electrons at two altitudes in the cusp, Lin et al. (1986) showed that some parallel potential drop is needed to explain the enhanced energy flux observed in the lower-altitude electrons, although we do not know whether their enhanced energy flux events are related to cusp moving auroral structures.

In this study, we demonstrated a one-to-one correspondence between the moving cusp auroral structure measured at a wavelength of $630.0 \mathrm{~nm}$ and the electron precipitation region responsible for its creation. This result will help develop the quantitative relation between the red line aurora intensity and soft precipitating electrons. In Regions $b$ and $c$, the integral electron energy flux increased to $2 \times 10^{11}$ to $4 \times 10^{11} \mathrm{eV} \mathrm{cm}^{-2} \mathrm{~s}^{-1} \mathrm{sr}^{-1}$, and the average energies at those times were approximately $2 \times 10^{2} \mathrm{eV}$ (see the black dots in the top two panels of Figure 3 for the corresponding interval). From the intensities of Auroras $B$ and $C$, we know that the electron precipitation with these characteristics created a 4.5 to $5 \mathrm{kR}$ red line emission.

\section{Conclusions}

Using data from the high-sensitivity all-sky imager at Longyearbyen, Svalbard, and particle data from the DMSP F18 spacecraft, we examined particle precipitation features in the early and final stages of a moving cusp auroral structure. We focused on two structures that occurred near noon, separated by approximately $3 \mathrm{~min}$, during a southwestward IMF condition. The second structure occurred when the IMF turned further southward. Immediately after the appearance of the latter structure, the two auroral structures were adjacently situated, and the DMSP F18 spacecraft passed through these regions.

To delineate the boundaries of different precipitating regions in the DMSP particle data, we introduced the ratio of the integral ion number flux to the integral electron number flux. Our investigation shows that the ion precipitation in the young cusp aurora had a high energy flux, while that in the old aurora had a very low energy flux. Regarding the electron precipitation, the features in both regions were found to be very similar: the energy fluxes at approximately $100 \mathrm{eV}$ often exceeded $1 \times 10^{9} \mathrm{eV} \mathrm{cm}^{-2} \mathrm{~s}^{-1} \mathrm{sr}^{-1} \mathrm{eV}^{-1}$ in both regions. From this study, we suggest that the precipitation of the electrons contained in the open flux tube is maintained at a high flux over a certain period of time from its beginning and the high flux of the electron precipitation is controlled by a mechanism independent of the ion precipitation.

\section{Abbreviations}

ACE: Advanced Composition Explorer; DMSP: Defense Meteorological Satellite Program; EMCCD: electron multiplier charge-coupled device; FTE: flux transfer event; GSE: geocentric solar ecliptic; GSM: geocentric solar magnetospheric; IMF: interplanetary magnetic field; MLAT: magnetic latitude; MLT: magnetic local time; SuperDARN: Super Dual Auroral Radar Network. 


\section{Competing interests}

The authors declare that they have no competing interests.

\section{Authors' contributions}

ST proposed the topic and analyzed the data. HK and YO facilitated the data analysis process and helped in data interpretation. HK and YO also collaborated with the corresponding author in the construction of manuscript. All authors read and approved the final manuscript.

\section{Acknowledgements}

We would like to thank Takeshi Aoki of the University of Electro-Communications for his maintenance of the all-sky imager. We also thank Fred Sigernes and Margit Dyrland for their help at the University Centre in Svalbard, Longyearbyen. Discussion with Dai Hasegawa of the University of Electro-Communications is acknowledged. The DMSP particle detectors were designed by Dave Hardy of AFRL, and the data were obtained from JHU/APL. GEOTAIL magnetic field data were provided by T. Nagai through DARTS at the Institute of Space and Astronautical Science, JAXA, in Japan. ACE magnetic field and plasma data were provided by N. Ness and D. McComas through the NASA CDAWeb. This work was supported by JSPS KAKENHI Grant Number 22340143.

\section{Author details}

${ }^{1}$ Department of Communication Engineering and Informatics, University of Electro-Communications, Chofu, Tokyo 182-8585, Japan. ${ }^{2}$ Center for Space Science and Radio Engineering, University of Electro-Communications, Chofu, Tokyo 182-8585, Japan. ${ }^{3}$ Now at Department of Geophysics, Graduate School of Science, Kyoto University, Kyoto 606-8502, Japan. ${ }^{4}$ National Institute of Polar Research, Tachikawa, Tokyo 190-8518, Japan.

Received: 13 October 2014 Accepted: 25 April 2015

Published online: 16 May 2015

\section{References}

Burch JL (1985) Quasi-neutrality in the polar cusp. Geophys Res Lett 12:469-472

Fairfield DH (1971) Average and unusual locations of the Earth's magnetopause and bow shock. J Geophys Res 76(28):6700-6716, doi:10.1029/JA076i028p06700

Fasel GJ (1995) Dayside poleward moving auroral forms: a statistical study. J Geophys Res 100(A7):11891-11905, doi:10.1029/95JA00854

Hardy DA, Schmidt LK, Gussenhoven MS, Marshall FJ, Yeh HC, Shumaker TL, Huber A, Pantazis J (1984) Precipitating electron and ion detectors (SSJ/4) for block 5D/flights 4-10 DMSP satellites: Calibration and data presentation. Tech Rep AFGL-TR-84-0317, Air Force Geophys Lab, Hanscom Air Force Base, Mass

Hardy DA, Gussenhoven MS, Holeman E (1985) A statistical model of auroral electron precipitation. J Geophys Res 90(A5):4229-4248, doi:10.1029/ JA090iA05p04229

Haerendel G, Paschmann G, Sckopke N, Rosenbauer H, Hedgecock PC (1978) The frontside boundary layer of the magnetosphere and the problem of reconnection. J Geophys Res 83(A7):3195-3216

Hosokawa K, Taguchi S, Ogawa Y, Aoki T (2013a) Periodicities of polar cap patches. J Geophys Res 118:447-453, doi:10.1029/2012JA018165

Hosokawa K, Taguchi S, Ogawa Y, Sakai J (2013b) Two-dimensional direct imaging of structuring of polar cap patches. J Geophys Res 118:6536-6543, doi:10.1002/ jgra. 50577

Hosokawa K, Taguchi S, Shiokawa K, Otsuka Y, Ogawa Y, Nicolls M (2014) Global imaging of polar cap patches with dual airglow imagers. Geophys Res Lett 41:1-6, doi:10.1002/2013GL058748

Khan H, Cowley SWH (1999) Observations of the response time of high-latitude ionospheric convection to variations in the interplanetary magnetic field using EISCAT and IMP-8 data. Ann Geophys 17:1306-1335, doi:10.1007/ s00585-999-1306-8

Lin CS, Burch JL, Winningham JD (1986) Near-conjugate observations of polar cusp electron precipitation using DE 1 and DE 2. J Geophys Res 91(A10):11186-11202, doi:10.1029/JA091iA10p11186

Lockwood MP, Sandholt E, Cowley SWH, Oguti T (1989) Interplanetary magnetic field control of dayside auroral activity and the transfer of momentum across the dayside magnetopause. Planet Space Sci 37(11):1347-1365, doi:10.1016/ 0032-0633(89)90106-2
Lockwood M, Smith MF (1994) Low and middle altitude cusp particle signatures for general magnetopause reconnection rate variations: 1. Theory J Geophys Res 99(A5):8531-8553, doi:10.1029/93JA03399

Milan SE, Lester M, Cowley SWH, Moen J, Sandholt PE, Owen CJ (1999) Meridian-scanning photometer, coherent HF radar, and magnetometer observations of the cusp: a case study. Ann Geophys 17:159-172

Oksavik K, Moen J, Carlson HC (2004) High-resolution observations of the small-scale flow pattern associated with a poleward moving auroral form in the cusp. Geophys Res Lett 31:L11807, doi:10.1029/2004GL019838

Oksavik K, Moen J, Carlson HC, Greenwald RA, Milan SE, Lester M, Denig WF, Barnes RJ (2005) Multi-instrument mapping of the small-scale flow dynamics related to a cusp auroral transient. Ann Geophys 23:2657-2670

Onsager TG, Kletzing CA, Austin JB, MacKiernan H (1993) Model of magnetosheath plasma in the magnetosphere: Cusp and mantle particles at low-altitudes. Geophys Res Lett 20:479-482, doi:10.1029/93GL00596

Owen CJ, Fazakerley AN, Carter PJ, Coates AJ, Krauklis IC, Szita S, Taylor MGGT, Travnicek P, Watson G, Wilson RJ, Balogh A, Dunlop MW (2001) Cluster PEACE observations of electrons during magnetospheric flux transfer events. Ann Geophys 19:1509-1522

Roble RE, Rees MH (1977) Time-dependent studies of the aurora: effects of particle precipitation on the dynamic morphology of ionospheric and atmospheric properties. Planet Space Sci 25(11):991-1010

Russell CT, Elphic RC (1978) Initial ISEE magnetometer results: magnetopause observations. Space Sci Rev 22:681-715, doi:10.1007/ BF00212619

Sakai J, Hosokawa K, Taguchi S, Ogawa Y (2014) Storm-time enhancements of $630.0 \mathrm{~nm}$ airglow associated with polar cap patches. J Geophys Res 119:2214-2228, doi:10.1002/2013JA019197

Sandholt PE, Deehr CS, Egeland A, Lybekk B, Viereck R, Romick GJ (1986) Signatures in the dayside aurora of plasma transfer from the magnetosheath. J Geophys Res 91(A9):10,063-10,079, doi:10.1029/JA091iA09p10063

Sandholt PE, Lockwood M, Oguti T, Cowley SWH, Freeman KSC, Lybekk B, Egeland A, Willis DM (1990) Midday auroral breakup events and related energy and momentum transfer from the magnetosheath. J Geophys Res 95(A2):1039-1060, doi:10.1029/JA095iA02p01039

Sandholt PE, Farrugia CJ (2003) Does the aurora provide evidence for the occurrence of antiparallel magnetopause reconnection? J Geophys Res 108(A12):1466, doi:10.1029/2003JA010066

Southwood DJ (1987) The ionospheric signature of flux transfer events. J Geophys Res 92(A4):3207-3213, doi:10.1029/JA092iA04p03207

Spreiter JR, Stahara SS (1980) A new predictive model for determining solar wind-terrestrial planet interactions. J Geophys Res 85(A12):6769-6777, doi:10.1029/JA085iA12p06769

Taguchi S, Sugiura M, Winningham JD, Slavin JA (1993) Characterization of the IMF $B_{Y}$-dependent field-aligned currents in the cleft region based on DE 2 observations. J Geophys Res 98(A2):1393-1407, doi:10.1029/92JA01014

Taguchi S, Hosokawa K, Suzuki S, Tawara A, Frey HU, Matzka J, Yukimatu AS, Sato N (2010) Plasma flow during the brightening of proton aurora in the cusp. J Geophys Res 115:A10308, doi:10.1029/2010JA015535

Taguchi S, Hosokawa K, Ogawa Y, Aoki T, Taguchi M (2012) Double bursts inside a poleward-moving auroral form in the cusp. J Geophys Res 117:A12301, doi:10.1029/2012JA018150

Yang YF, Lu JY, Wang JS, Peng Z, Zhou L (2013) Influence of interplanetary magnetic field and solar wind on auroral brightness in different regions. J Geophys Res 118:209-217, doi:10.1029/2012JA017727

\section{Submit your manuscript to a SpringerOpen ${ }^{\circ}$ journal and benefit from:}

- Convenient online submission

- Rigorous peer review

- Immediate publication on acceptance

- Open access: articles freely available online

- High visibility within the field

- Retaining the copyright to your article

Submit your next manuscript at $>$ springeropen.com 